\title{
Enhancing Conceptual Transfer of Mathematical Concepts and Motivating Students using Engineering Performance Tasks
}

\author{
Yacob Astatke, Pamela Leigh-Mack, Solomon Alao, Craig J. Scott, \\ Alicia Davis, A. Bert Davy, Erastus Njage, Masud Salimian \\ Morgan State University \\ Baltimore, Maryland
}

\begin{abstract}
This paper presents a discussion of the usage of engineering performance tasks in two sections of an innovative Pre-Calculus course to enhance conceptual transfer while motivating engineering students. A description of the entire process from concept to implementation is given including: 1) the role of performance tasks in general; 2) the faculty development that occurred; 3) engineering performance tasks and their development; 4) performance tasks implementation; and 5) assessment and evaluation. Specific reasoning processes and mental habits associated with the Dimensions of Learning pedagogy are designed in the performance tasks, and are presented. Aligning the performance tasks with the topics covered in the lecture is the approach taken, and details of this process are provided. Results are positive.

Approximately ninety percent $(90 \%)$ of the students were proficient at solving the engineering performance tasks. Formative assessment results of the two-minute paper indicated that students understood and could explain the specific procedural and declarative knowledge addressed. In addition, the instructional framework increased students' Pre-Calculus knowledge, and confidence for solving Pre-Calculus and engineering problems. These results were validated by the use of Pair Sample T-tests. The results of this study have implications for improving conceptual transfer of mathematical concepts and motivating engineering students.

\section{Introduction}

Institutions have developed various strategies for motivating students and exposing them to engineering, including the use of freshmen engineering design courses. On the other hand, some institutions have used a "just in time" approach in teaching the necessary mathematics for engineering in order to spark students' interest and because of the difficulty students have in negotiating mathematics courses, particularly early in their program ${ }^{1}$. Moreover, when students initially take engineering courses, they often have difficulty applying mathematical concepts and knowledge to solve engineering problems. This paper presents a performance assessment approach to improve motivation and to enhance learning and conceptual transfer of mathematics concepts, using performance tasks and rubrics in an innovative Pre-Calculus course. A multidisciplinary team of faculty from the Schools of Engineering, Science, and Education collaborated in order to develop a series of performance tasks in the disciplines of civil, electrical and industrial engineering. The performance tasks incorporate the Dimensions of Learning (DOL) pedagogical framework, which is a powerful, effective and comprehensive model of five dimensions that uses what researchers and theorists know about learning to define the learning process. ${ }^{2}$
\end{abstract}


The innovative Pre-Calculus course, developed and taught using the pedagogical framework previously mentioned, was initially offered in the Fall 2003 semester. The fourcredit course consisted of a lecture component that met four days per week, fifty minutes each day. In the Fall of 2004, a well-developed set of performance tasks were added to the course which necessitated a format change. A mathematics faculty continued to teach the lecture part of the course, and an engineering faculty taught the added laboratory component, where the performance tasks were implemented. No additional course credit was given for the added twohour laboratory component, which met once a week. The fifty-two engineering freshmen enrolled in the course were selected based on their placement exam results. Basic Algebra, PreCalculus I, Comprehensive Pre-Calculus and Calculus I are the possible entry courses for new freshmen. The innovative Pre-Calculus course content was most closely aligned with the University's Comprehensive Pre-Calculus course. Students who were Comprehensive PreCalculus or Pre-Calculus I ready, based on their placement tests scores, were placed in the special course. Some who placed in Basic Algebra were placed in the course as well, considering their high school Pre-Calculus or Calculus exposure and course grades.

The mathematics instructor identified the non-negotiable Pre-Calculus concepts and a questionnaire for the participants was developed based on this. A pre-test and post-test design was used to determine the effects of the instructional framework on outcomes. The tests were scored using a rubric.

\section{Role of Performance Tasks}

A performance task is a performance assessment mechanism. It is a carefully constructed activity or project designed to achieve a viable goal or outcome, and to enhance the knowledge, skills and dispositions of all students. In other words, performance tasks are assignments and projects used to provide students with practice necessary to determine competency in the skills and knowledge deemed important. A carefully constructed activity is one where assurance is made that "what students should know and be able to do" has been identified, and the tasks are developed to accomplish this. According to Danielson and Marquez ${ }^{3}$, they may be used for assessment and instructional purposes. Good performance tasks are engaging; are realistic, elicit knowledge and skill, enable assessment of individuals, and contain clear directions to the students. Because of its role, the performance task was selected as one of the assessment mechanisms to be used in the innovative Pre-Calculus course.

\section{Dimensions of Learning (DOL) Pedagogical Framework}

The pedagogy used in the course is based on the Dimensions of Learning (DOL) framework. A detailed discussion of the initial work performed using the DOL pedagogical framework during the Fall of 2003 has been previously reported ${ }^{4}$. The performance tasks were developed within this framework as well. Robert Marzano ${ }^{2}$ lead the development of this framework which has a premise that five types of thinking, or five "dimensions of learning," are essential to successful learning. The framework grew out of many years of research into how we learn most effectively, and is designed to translate research into a practical classroom application to improve teaching and learning in any content area ${ }^{2,5}$. The five dimensions of learning include 1) Positive Attitudes and Perceptions about Learning; 2) Thinking Involved in Acquiring and Integrating Knowledge; 3) Thinking Involved in Extending and Refining Knowledge; 4) Thinking Involved in Using Knowledge Meaningfully; and 5) Productive Habits of the Mind.

\footnotetext{
"Proceedings of the 2005 American Society for Engineering Education Annual Conference \& Exposition
} Copyright $\mathbb{C}$ 2005, American Society for Engineering Education" 
From an engineering perspective, DOL3 and DOL4 were thought to be most applicable to conceptual understanding and being able to transfer the knowledge from mathematics to engineering. Dimension 3 indicates that once knowledge is acquired, it can then be extended and refined by applying reasoning processes of comparing, classifying and abstracting. Learners rigorously analyze what they learn by applying these reasoning processes that will help them extend and refine information. Once this has occurred, the knowledge can be used meaningfully, as denoted by Dimension 4. In this dimension, performance tasks can be constructed around the reasoning processes of decision-making; problem solving; invention; experimental inquiry; investigation; and system analysis. It was a requirement that these two dimensions be included in performance tasks development. For each of these two dimensions, performance tasks were created with particular reasoning processes in mind. Since the performance tasks are based on declarative knowledge (what students should know) and procedural knowledge (what students should be able to do), DOL2 is naturally a part of the performance tasks.

\section{Faculty Development and Training}

It was planned that engineering students from the three departments of civil engineering (CE); electrical and computer engineering (ECE) ; and industrial, manufacturing; and information engineering (IMIE) would be enrolled in the innovative Pre-Calculus course. In order to ensure that the performance tasks were interesting to all student students from the three departments, a diverse set of performance tasks were developed by involving faculty from each of the three disciplines. This included two from ECE, one from CE and one from IMIE. In addition, the mathematics and engineering instructors, the project director and two other mathematics faculty all received training. Faculty received training in three areas including 1) the Discourse software; 2) the Dimensions of Learning pedagogy; 3) performance assessment (including performance tasks); and 4) rubric development. Although not all faculty was going to use all of these components as it related to the course, it was desirous that everyone had a good understanding of all aspects of the project underway. In addition, this armed faculty with new tools and education that could be incorporated in the engineering and mathematics courses that they normally teach. During the summer of 2004, ETS personnel provided a 2-day workshop on Discourse, and the education faculty member conducted assessment and pedagogy workshops, all which occurred over a two-week period. The remainder of the summer was used for performance tasks development, and the education faculty continued to provide guidance.

\section{Engineering Performance Tasks and their Development}

Prior to the creation of the performance tasks, a reexamination of the desired course content was performed. Since a multidisciplinary team of engineering faculty was involved in the project, a review ensured that each Department had input on the mathematics topics deemed most important. The learning outcomes (the declarative and procedural knowledge) were established and the order of material coverage was decided. The approach used in developing the engineering performance tasks was to align the course topics, and the associated declarative and procedural knowledge, with the learning outcomes created for the performance tasks. Within this approach, care was taken to give the performance tasks an experiential perspective. A daily course schedule was created so that the weekly performance tasks would align with the weekly topics covered in the lecture part of the course taught by the mathematics faculty. The knowledge covered in the lecture part of the course was reinforced in the laboratory, while

\footnotetext{
"Proceedings of the 2005 American Society for Engineering Education Annual Conference \& Exposition
} Copyright $\mathbb{C}$ 2005, American Society for Engineering Education" 
simultaneously meeting the other objectives of the project. Table 1 provides the format that was used for the performance tasks. Tables 2 and 3 illustrate the alignment of topics. Notice that the declarative and procedural knowledge, highlighted in bold and italics in Table 2, are indicated in the learning outcomes of the performance tasks in Table 3.

Table 1. Format of Performance Tasks

\begin{tabular}{|c|c|}
\hline \multicolumn{2}{|r|}{ Engineering Performance Task-Unit Number } \\
\hline I. & Engineering Topic \\
\hline \multirow[t]{3}{*}{ II. } & Learning Outcomes (DOL 2) \\
\hline & Declarative Knowledge. \\
\hline & Procedural Knowledge \\
\hline \multirow[t]{2}{*}{ III. } & $\begin{array}{l}\text { Thinking or Reasoning Processes } \\
\text { (DOL 3) }\end{array}$ \\
\hline & (DOL4) \\
\hline \multirow[t]{4}{*}{ IV. } & Description of Performance Task \\
\hline & Engineering Context* \\
\hline & Directions to the Student \\
\hline & Mathematical Concepts \\
\hline V. & Rubric \\
\hline VI. & Performance Tasks Solution \\
\hline $\begin{array}{l}* \text { In cases } \\
\text { prior to } \mathrm{g}\end{array}$ & $\begin{array}{l}\text { ere more background is needed, the engineering context is provided } \\
\text { g directions to the student. }\end{array}$ \\
\hline
\end{tabular}

Unit3. Functions

Table 2. Excerpt from Pre-Calculus Learning Outcomes

It is expected that the student will:

\begin{tabular}{|c|c|c|}
\hline Topic/Concept & Declarative Knowledge & Procedural Knowledge \\
\hline - $\quad$ The Function Concept & $\begin{array}{l}\text { - Know what a function is. } \\
\text { - Know function notation } \\
\text { Know the effect that } \\
\text { transformations have on } \\
\text { both the equation and graph } \\
\text { of a function }\end{array}$ & $\begin{array}{l}\text { Be able to determine if a } \\
\text { relationship given in the } \\
\text { form of a table of values is } \\
\text { a function. } \\
\text { Be able to evaluate } \\
\text { functions at numerical and } \\
\text { algebraic expressions. } \\
\text { Be able to find the domain } \\
\text { of a function algebraically. }\end{array}$ \\
\hline - Graphs of Functions & $\begin{array}{l}\text { Know how the vertical line } \\
\text { test is used to determine if } \\
\text { an equation is a function. } \\
\text { Know the basic graph of a } \\
\text { linear and quadratic } \\
\text { function }\end{array}$ & $\begin{array}{l}\text { - Be able to sketch the graph } \\
\text { of a function using point } \\
\text { plotting (and technology). } \\
\text { - } \quad \text { Be able to determine if a } \\
\text { relationship given in the } \\
\text { form of an equation or a } \\
\text { graph is a function. } \\
\text { Be able to solve applied } \\
\text { problems using functions. }\end{array}$ \\
\hline
\end{tabular}


Table 3. Excerpt from Sample Engineering Performance Task

\section{Engineering Performance Task - Pre-Calculus Unit 3 \\ The Function Concept, Graphs of Functions \\ July 2004}

\section{Engineering Topic}

Sizing pipes for a sewer line based on the required flow volume.

\section{Learning Outcomes (DOL 2)}

Declarative knowledge

1) The student knows the function notation.

2) The student knows how to prepare a graph of a function

3) The student knows how to use the vertical line test to determine if a curve is a graph of a function.

Procedural knowledge

1) The student is able to evaluate functions of numerical and algebraic expressions.

2) The student is able to sketch the graph of a function using point plotting.

3) The student is able to solve applied problems using functions

\section{Engineering Performance Tasks Implementation}

The Engineering Performance Tasks (EPT) were conducted for the two innovative PreCalculus sections once a week for a two-hour period. The students completed ten EPTs (6 electrical, 2 civil, and 2 industrial engineering), ten two-minute paper performance assessment surveys using the Discourse software, and took a mid-term exam that had the same format as the engineering performance task. Discourse is an instructional delivery software which creates an interactive learning environment. For the instructor, Discourse provides immediate assessment, immediate observation of student progress and instructor control that allow for faster adjustments in order to impact student performance. The two-minute paper allowed students to give the instructor feedback from the day's lesson and indicated any areas of difficulties that still remained. The instructor used this formative assessment to explain areas of concern prior to moving to the next performance task. Although the EPTs incorporated only three of the five Dimensions of Learning, the instructor used all five dimensions as a pedagogical framework. The list of performance tasks, excluding the mid-term examination EPT, is provided in Table 4.

The EPT laboratory sessions were conducted in two parts. During the first hour, the instructor used power-point presentations with pictures, animations, or short movies to introduce the engineering concept that was discussed in the EPT. This was done in accordance with Dimension 1 of the DOL teaching paradigm in order to help the students "Acquire Positive Attitudes and Perceptions" about the engineering performance tasks (EPT). The instructor also helped the students in reading the EPT and extracting the key concepts that allowed them to solve the problem at hand. This was done in accordance with Dimension 2 to help students "Acquire and Integrate Knowledge." The role of the instructor was to provide guidance to relate the mathematics concept covered in the EPT to what students learned in the lecture component of the course.

During the second hour of the laboratory, the students completed the engineering performance task by using the various mathematics concepts to solve the engineering problems. They completed five EPT in groups of two and three and the other five individually. The students solved the EPT by hand and also used 25 HP notebooks with wireless connections to 
solve any performance task that required the use of software to plot the results. Seventy percent of the engineering performance tasks required the use of software like Microsoft Excel to create plots of lines, exponential functions, and parabolas. This was done in accordance with Dimensions 3 and 4 to help students "Extend and Refine Knowledge," and "Use knowledge Meaningfully." The goal was to enhance their knowledge and skills of the Pre-Calculus concepts as they are applied to solve engineering problems.

At the end of each performance task, students submitted a well-written paper that included not only the mathematical solution, but also a detailed explanation of all the steps required to solve the performance task. Being able to explain a solution provided the instructor an indication of the level of conceptual understanding the student had. Also, students improved their writing skills and learned that in engineering, documentation and presentation of the solution are as important as the solution itself. This was done in accordance to Dimensions 5 to help the students acquire "Productive Habits of Mind."

The engineering performance tasks (EPT) were graded using rubrics that were part of the performance assessment framework. All EPTs were assessed using a four level rubric: level 0 novice; level 1- apprentice; level 2 - practitioner; and level 3 - expert. The four levels were used to assess student performance in three different areas: understanding of the problem, strategy/reasoning/procedure used to solve the problem, and communication or explanation of the solution to the problem.

Table 4. Engineering Performance Tasks Completed

\begin{tabular}{|c|c|c|}
\hline EPT Area & EPT Engineering Concept & EPT Math Concept \\
\hline ECE & $\begin{array}{l}\text { Electrical Current, Charge, and } \\
\text { Energy Calculations }\end{array}$ & Exponents and Radicals Part\#1 \\
\hline IMIE & $\begin{array}{l}\text { Solidification Time of Cast Materials } \\
\text { in Sand Casting }\end{array}$ & Exponents and Radicals Part\#2 \\
\hline $\mathrm{CE}$ & $\begin{array}{l}\text { Calculations of Area and Lengths of } \\
\text { Sides of a Tract Land }\end{array}$ & Algebra with Polynomials \\
\hline ECE & $\begin{array}{l}\text { Battery Depletion Through Parasitic } \\
\text { Losses }\end{array}$ & Equation of Lines \\
\hline ECE & $\begin{array}{l}\text { Understanding Moore's Law and How } \\
\text { to Graph and Analyze Integrated } \\
\text { Circuit Production }\end{array}$ & Coordinate Geometry \\
\hline ECE & Mixing Digital Music Signals & Transformation of functions \\
\hline $\mathrm{CE}$ & $\begin{array}{l}\text { Sizing Pipes for a Sewer Line Based } \\
\text { on the Required Flow Volume }\end{array}$ & Graphs of Functions \\
\hline IMIE & $\begin{array}{l}\text { Minimizing the cost of production in } \\
\text { manufacturing of an oil storage tank. }\end{array}$ & Composition of Functions \\
\hline ECE & $\begin{array}{l}\text { Design of a Direct Broadcast Satellite } \\
\text { Dish Antenna }\end{array}$ & Quadratic Functions \\
\hline ECE & Synthesizing Sound Effects for Toys & $\begin{array}{l}\text { Exponential, Log and Trig } \\
\text { Functions }\end{array}$ \\
\hline
\end{tabular}




\section{Discussion and Results}

Results were positive. Table 5 provides the two-minute paper results from four of the ten engineering performance tasks, which are a typical representation of all the performance tasks. Results show that students believe that they understand and can explain the specific procedural and declarative knowledge addressed. The specific degree of comfort and the interest depended on the performance tasks and range from nearly seventy percent $(70 \%)$ to over ninety percent $(90 \%)$. Figure 1 shows the class average rubric score for each performance task. On a 3.0 rubric scale, the levels of performance are as follows: 2.5 and above represents high proficiency; greater than or equal to 2.0 and less than 2.5 is moderate proficiency; greater than or equal to 1.5 and less than 2.0 indicates low proficiency; and lower than 1.5 indicates a lack of proficiency. Figure 2 illustrates that eighty-five percent (85\%) of the mean rubric scores on the performance tasks were at the moderate to high proficiency level. Further examination of each student's score on each of the performance tasks showed that approximately ninety percent $(90 \%)$ of the students were proficient at solving the engineering performance tasks. These results indicate a conceptual transfer of the mathematical concepts and knowledge into the engineering domain.

The pre-test and post-test design was used to determine the effects of the instructional framework on the outcomes of knowledge and skills, disposition and conceptual transfer. The questionnaire consisted of fifteen questions related to the outcomes. The Paired Sample T-test, in accordance with the research design, was used to determine if there was a statistical significance difference between the pre- and post-test means or measures of the outcomes. Tables 6 through 8 indicate that a significant difference exist between the two means at the .01 level of significance for each of the outcomes. That is, the chances of the null hypothesis being true are less than 1 out of 100. Participants improved their knowledge and skills, improved their level of confidence for solving Pre-Calculus problems, and compared to high school, were afforded more opportunities to apply their acquired knowledge to solving mathematics content specific or engineering related problems.

\section{Conclusion}

It is believed that there is a reciprocal relationship between the instructional framework and the performance tasks. The performance tasks gave students real-life engineering situations for problem solving. Overall, student interest and participation were excellent. The use of performance tasks as a means of motivating students, enhancing conceptual transfer, and improving conceptual understanding was shown to be very promising. It is a direct measure and really forces the instructor to determine what learning outcomes are being sought. It also provides the instructor more information about the level of understanding that students have. 
Table 5. Two-Minute Paper Results

\begin{tabular}{|c|c|}
\hline Performance Task: Battery Depletion through Parasitic Losses $N=45$ & SA or $A^{*}$ \\
\hline $\begin{array}{l}\text { I understood all of the parts of the questions associated with this performance task, and can provide } \\
\text { appropriate solutions to all of the questions? }\end{array}$ & $82 \%$ \\
\hline $\begin{array}{l}\text { I understood all of the parts of the questions associated with this performance task, and can provide } \\
\text { appropriate solutions to all of the questions? }\end{array}$ & $93 \%$ \\
\hline $\begin{array}{l}\text { I can clearly explain how to answer the math questions in this performance task related to finding the } \\
\text { slope of a line given two points? }\end{array}$ & $87 \%$ \\
\hline $\begin{array}{l}\text { I can clearly explain how to answer the math questions in this performance task related to finding the } \\
\text { equation of a line using the slope intercept form? }\end{array}$ & $91 \%$ \\
\hline This performance task is very interesting? & $87 \%$ \\
\hline $\begin{array}{l}\text { The class discussion, and lecture conducted before the start of the performance task improved my } \\
\text { understanding of the problems related to this performance task? }\end{array}$ & $85 \%$ \\
\hline \multicolumn{2}{|l|}{ Performance Task: Mixing Digital Music Signals $N=47$} \\
\hline $\begin{array}{l}\text { I understood all of the parts of the questions associated with this performance task, and can provide } \\
\text { appropriate solutions to all of the questions? }\end{array}$ & $91 \%$ \\
\hline $\begin{array}{l}\text { I can clearly explain how to answer the math questions in this performance task related to sketching a } \\
\text { graph using the point plotting method. }\end{array}$ & $87 \%$ \\
\hline $\begin{array}{l}\text { I can clearly explain how to answer the math questions in this performance task related to plotting a } \\
\text { graph using technology (Microsoft excel)? }\end{array}$ & $81 \%$ \\
\hline $\begin{array}{l}\text { I can clearly explain how to answer the math questions in this performance task related to using } \\
\text { Microsoft excel to enter an equation and plotting the results? }\end{array}$ & $89 \%$ \\
\hline $\begin{array}{l}\text { I can clearly explain how to answer the math questions in this performance task related to function } \\
\text { notations and the effect of the transformations on the graph of a function? }\end{array}$ & $76 \%$ \\
\hline $\begin{array}{l}\text { I can clearly explain how to answer the math questions in this performance task related to solving an } \\
\text { equation involving exponents analytically (i.e. by hand)? }\end{array}$ & $83 \%$ \\
\hline This performance task is very interesting. & $91 \%$ \\
\hline \multicolumn{2}{|l|}{ Performance Task: Solidification Time of Cast Materials in Sand Casting $\mathrm{N}=\mathbf{2 5} * *$} \\
\hline $\begin{array}{l}\text { I understood all of the parts of the questions associated with this performance task, and can provide } \\
\text { appropriate solutions to all of the questions? }\end{array}$ & $84 \%$ \\
\hline $\begin{array}{l}\text { I can clearly explain how to answer all of the questions included in this performance task, and can use } \\
\text { math notations, such as exponents, equations with exponents, etc.... to demonstrate my understanding. }\end{array}$ & $88 \%$ \\
\hline This performance task is very interesting? & $76 \%$ \\
\hline \multicolumn{2}{|l|}{ Performance Task: Sizing Pipes for a Sewer Line Based on the Required Flow Volume $N=22 * *$} \\
\hline $\begin{array}{l}\text { I understood all of the parts of the questions associated with this performance task, and can provide } \\
\text { appropriate solutions to all of the questions? }\end{array}$ & $73 \%$ \\
\hline $\begin{array}{l}\text { I can clearly explain how to answer the math questions in this performance task related to plot a graph } \\
\text { using technology (Microsoft excel)? }\end{array}$ & $77 \%$ \\
\hline $\begin{array}{l}\text { I can clearly explain how to answer the math questions in this performance task related to using } \\
\text { Microsoft excel to enter an equation and plotting a graph using point plotting? }\end{array}$ & $77 \%$ \\
\hline $\begin{array}{l}\text { I can clearly explain how to answer the math questions in this performance task related to using } \\
\text { functions to solve applied problems (example: finding the size of the pipe)? }\end{array}$ & $78 \%$ \\
\hline This performance task is very interesting? & $68 \%$ \\
\hline
\end{tabular}

*SA-strongly agree; A-agree

** Only one section performed the performance task due to technology-related issues 


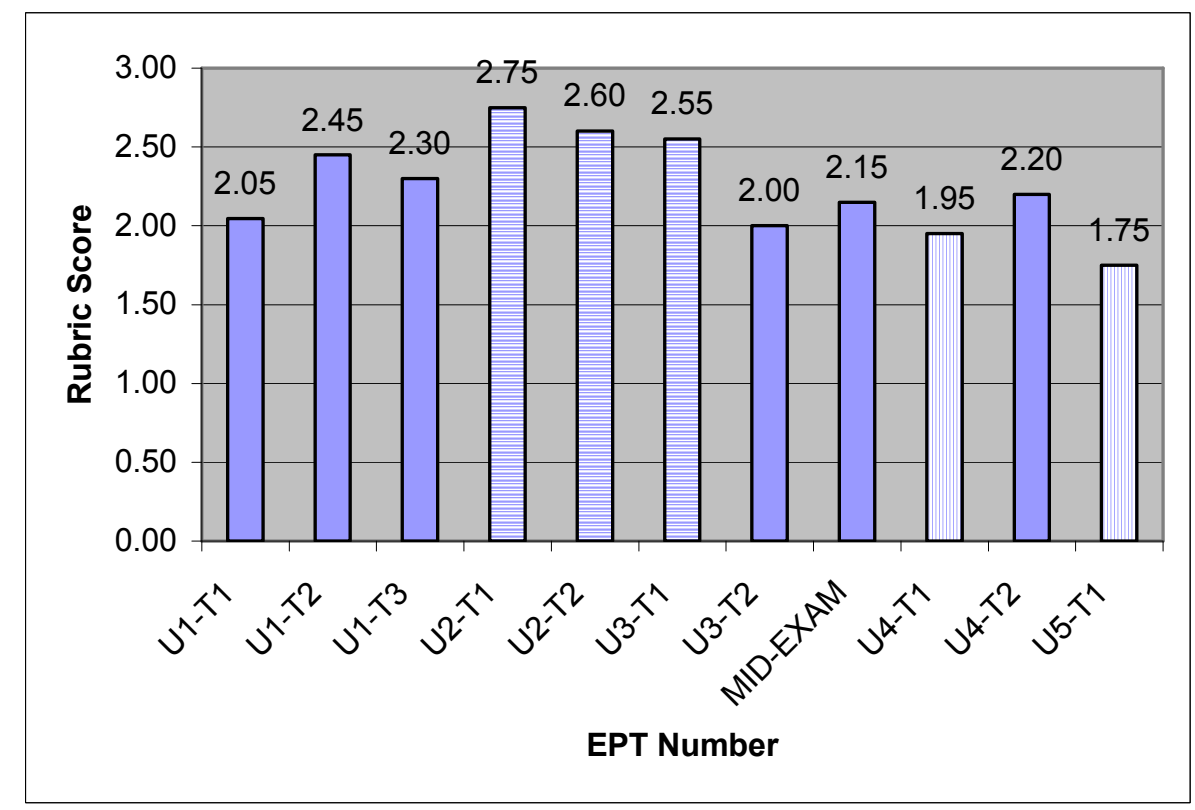

Figure 1. Level of student performance on the EPTs

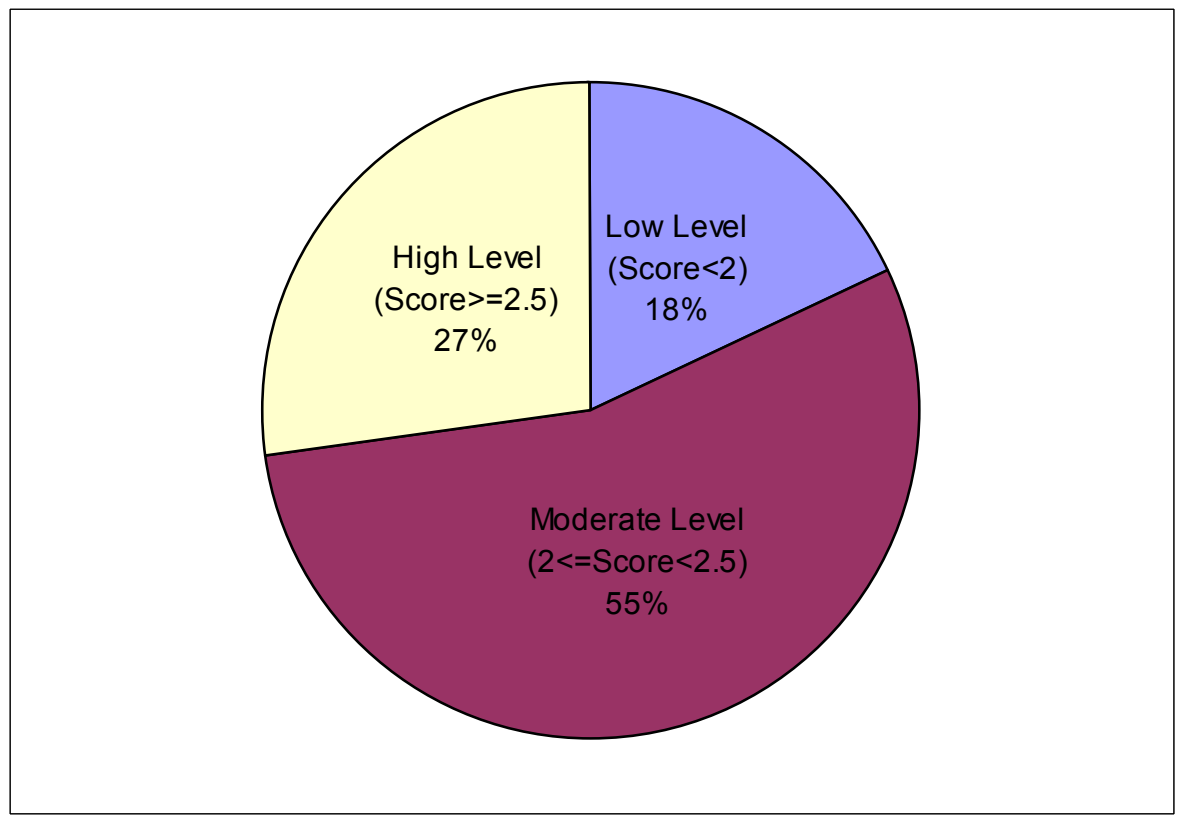

Figure 2. Distribution of the levels of performance on the EPT

Table 6. Paired Sample T-test for Knowledge and Skills

\begin{tabular}{|llccc|}
\hline Nature of Test & $\mathrm{N}$ & $\mathrm{M}$ & $\mathrm{SD}$ & $\mathrm{t}$ \\
\hline Pre-test & 41 & 0.898 & 0.38 & $\mathrm{p}<0.01$ \\
& & & & \\
Post-test & 41 & 1.495 & 0.34 & \\
\hline
\end{tabular}


Table 6. Paired Sample T-test for Confidence of Solving Pre-Calculus Problems

\begin{tabular}{|llccc|}
\hline Nature of Test & $\mathrm{N}$ & $\mathrm{M}$ & $\mathrm{SD}$ & $\mathrm{t}$ \\
\hline Pre-test & 41 & 2.984 & 0.40 & $\mathrm{p}<0.01$ \\
& & & & \\
Post-test & 41 & 3.305 & 0.34 & \\
\hline
\end{tabular}

Table 7. Paired Sample T-test for Opportunities for Solving Engineering Problems

\begin{tabular}{|llccc|}
\hline Nature of Test & $\mathrm{N}$ & $\mathrm{M}$ & $\mathrm{SD}$ & $\mathrm{t}$ \\
\hline Pre-test & 41 & 1.854 & 1.15 & $\mathrm{p}<0.01$ \\
& & & & \\
Post-test & 41 & 3.342 & 0.91 & \\
\hline
\end{tabular}

\section{Bibliography}

1. Klingbell, N.W., Mercer, R.E., Rattan, K.S., Raymer, M. L., Reynolds, D.B., Rethinking Engineering Mathematics Education: A Model for Increased Retention, Motivation and Success in Engineering, Proceedings of the ASEE Annual Conference, 2004.

2. Marzano, R. J., A different kind of classroom: Teaching with Dimensions of Learning. Alexandria, VA: ASCD, 1992.

3. Danielson, Charlotte, Marquez, Elizabeth, A Collection of Performance Tasks and Rubrics: High School Mathematics, Eye of Education, Inc., 1998.

4. Leigh-Mack, P., Farmer, S., Alao, S., Scott, C., N'Guerekata, G., Improving Retention by Redesigning Freshmen Mathematics with the Dimensions of Learning Pedagogy, Proceedings of the ASEE Annual Conference, 2004.

5. Marzano, R., Pickering, D., \& McTighe, J., Assessing student outcomes: Performance assessment using the dimensions of learning model. Alexandria, VA: Association for Supervision and Curriculum Development (ASCD), 1993.

\section{Biographical Sketches}

Yacob Astatke is an Instructor in the Electrical and Computer Engineering Department at Morgan State University. He received his B.S.E.E. from Morgan State University, and his M.S.E.E. from Johns Hopkins University. His teaching interests include electric circuits, and communications theory. His research interests include wireless communication and web-based course development.

Pamela Leigh-Mack is an Associate Professor and Chair of the Department of Electrical and Computer Engineering at Morgan State University. She received a B.S. degree in mathematics in 1980 from Virginia Union University, B.S.E.E. and M.S.E.E degrees from Howard University in 1980 and 1982, respectively, and a Ph.D. in 1991 from the University of Delaware. Her research interests include engineering education and women in engineering.

Solomon Alao is an Associate Professor of Teacher Education and Administration at Morgan State University. He received his B.S. degree in Recreation and Administration from Delaware State University in 1991 and his Ph.D. in Human Development (Ed-psych) from the University of Maryland in 1997. His research interests include human

"Proceedings of the 2005 American Society for Engineering Education Annual Conference \& Exposition Copyright (C) 2005, American Society for Engineering Education” 
motivation and learning; student achievement motivation; conceptualization of knowledge; assessment; and curriculum leadership.

Craig Scott is an Associate Professor of Electrical and Computer Engineering at Morgan State University. He received his B.S.E.E. degree in 1979 from Howard University, his M.S.E.E. in 1981 from Cornell University and a $\mathrm{Ph} . \mathrm{D}$. in electrical engineering from Howard University in 1991. His research interests are in the areas of immersive engineering visualization tools for nanometric scale material investigations; visualization of tactical electronic systems environments; and mobile learning technologies.

Alicia Davis is a Lecturer in the Department of Mathematics at Morgan State University. She received her B.S. degree in mathematics from Jackson State University in 1997 and an M.S. degree in mathematics from Texas A\&M University-College Station in 2000. Her research interests are in the areas of mathematics education and innovative pedagogical approaches.

A. Bert Davy is an Assistant Professor of Civil Engineering at Morgan State University. He received his B.S. in Mathematics and Physics from the University of the West Indies, Barbados in 1971 and a B.S. degree in Civil Engineering from Queen's University in Kingston, Ontario, Canada in 1978. Dr. Davy obtained his M.S. in Structural Engineering from the University of Maryland in 1984. His doctorate degree was earned in 2004 from Morgan State University. His research interests include adaptive structures and control technology, earthquakeresistant structures, and engineering performance tasks and dimensions of learning.

Erastus Njage is an Instructor in the Department of Electrical and Computer Engineering at Morgan State University. He received his B.S. degree in electrical engineering from Howard University and a M.S. degree from the Massachusetts Institute of Technology in 1984 and 1986, respectively. His research interests are in the areas of digital systems design and digital signal processing.

Masud Salimian is a Lecturer of Industrial, Manufacturing \& Information Engineering at Morgan State University. He received his B.S. degree in industrial engineering from Sharif University of Technology in 1976, and his M.S. and Ph.D. degrees in Industrial Engineering from the University of Oklahoma in 1985 and 1988, respectively.

His research interests are in engineering education, teaching innovation, multimedia instructional design and distant learning, modern manufacturing processes, applications of optimization and simulation in manufacturing systems, and product design. 
Appendix.

\section{Sample Engineering Performance Task - Pre-Calculus Unit 3 The Function Concept, Graphs of Functions \\ July 2004}

\section{Engineering Topic}

Sizing pipes for a sewer line based on the required flow volume.

\section{Learning Outcomes (DOL 2)}

Declarative knowledge

1) The student understands the function notation.

2) The student understands how to prepare a graph of a function

3) The student understands how to use the vertical line test to determine if a curve is a graph of a function.

Procedural knowledge

1) The student is able to evaluate functions of numerical and algebraic expressions.

2) The student is able to sketch the graph of a function using point plotting.

3) The student is able to solve applied problems using functions

\section{Thinking or Reasoning Processes}

(DOL 3) Classifying expressions as functions. Using inductive reasoning to draw and support conclusions about values computed. Using deductive reasoning to determine if all computed values were valid in the context of the problem. Abstracting a pattern of information when selecting required size of pipe.

(DOL 4) Decision making in selecting the correct pipe size. Problem solving using the data provided.

\section{Description of Performance Task Directions to the student}

An engineer needs to determine the size of a pipe required to carry sewerage away from a street in a new development. There are 40 single family residences planned for the street and the average family size is $4 \frac{1}{2}$ persons. The average daily water usage is estimated at 70 gallons per person. Assume that all water used is discharged to the sewer.

The amount of water, $\mathrm{Q}$, in $\mathrm{ft}^{3} / \mathrm{sec}$, that a pipe flowing full can accommodate is given by

$$
\mathrm{Q}=0.432 \mathrm{CD}^{2.63} \mathrm{~S}^{0.54}
$$

where $\mathrm{C}$ is a coefficient that depends on the roughness of the inside of the pipe, $\mathrm{S}$ depends on the slope of the pipe and $\mathrm{D}$ is the inside diameter of the pipe, measured in feet.. For this project concrete-lined pipe is to be used so that $\mathrm{C}$ $=120$, and for the street $\mathrm{S}=0.15 \mathrm{ft} / \mathrm{ft}$.

a. Write $\mathrm{Q}$ as a function of $\mathrm{D}$.

b. If the pipe is only available in size of 2" to 24" in inside diameter in increments of 2", plot Q as a function of $\mathrm{D}$ for the range of available pipe sizes.

c. Use the vertical line test to determine if the curve is the graph of a function.

d. Select the correct pipe size that should be used for the sewer line (1) based on the average discharge flow rate (2) based on a Superbowl halftime discharge flow which is twelve times the average discharge rate.

\section{Mathematical Concept}

write

A function $f$ is a rule that assigns each element in a set A to exactly one element in a set. For example we

$$
\mathrm{A}(\mathrm{r})=\pi \mathrm{r}^{2}
$$

when stating that the area of a circle is a function of its radius. Each value of the radius $r$, is assigned to exactly one value of the area $\mathrm{A}$.

One way to represent a function is by an explicit algebraic function. Another way is to represent it graphically. Both representations are utilized here.

The vertical line test establishes that a vertical line drawn on the graph does not intersect curve more than once.

"Proceedings of the 2005 American Society for Engineering Education Annual Conference \& Exposition Copyright $\mathbb{C}$ 2005, American Society for Engineering Education" 


\section{Rubric}

\begin{tabular}{|c|c|c|c|c|}
\hline $\begin{array}{c}\text { Criteria } \\
\text { (or elements) }\end{array}$ & $\begin{array}{c}0 \\
\text { (Novice) } \\
\text { Makes an effort. } \\
\text { No Understanding. }\end{array}$ & $\begin{array}{c}1 \\
\text { ( Apprentice) OK, } \\
\text { good try. Unclear } \\
\text { if student } \\
\text { understands. }\end{array}$ & $\begin{array}{c}2 \\
\text { (Practitioner) Very } \\
\text { good. Clear. } \\
\text { Strong } \\
\text { understanding. }\end{array}$ & $\begin{array}{c}3 \\
\text { (Expert) Wow. } \\
\text { Awesome! Excellent } \\
\text { understanding. }\end{array}$ \\
\hline $\begin{array}{l}\text { 1) Understands the } \\
\text { function notation. }\end{array}$ & $\begin{array}{l}\text { Cannot identify a } \\
\text { function by its } \\
\text { notation. }\end{array}$ & $\begin{array}{l}\text { Understands the } \\
\text { notation for only } \\
\text { one side of the } \\
\text { expression }\end{array}$ & $\begin{array}{c}\text { Clearly } \\
\text { understands the } \\
\text { structure of the } \\
\text { notation. }\end{array}$ & $\begin{array}{l}\text { Clearly understands } \\
\text { and can explain the } \\
\text { structure of the } \\
\text { notation. Offers } \\
\text { correct examples. }\end{array}$ \\
\hline $\begin{array}{l}\text { 2) Understands } \\
\text { how to prepare a } \\
\text { graph of a function }\end{array}$ & $\begin{array}{c}\text { Cannot explain } \\
\text { how to prepare a } \\
\text { graph of a function }\end{array}$ & $\begin{array}{l}\text { Understands some } \\
\text { but not all of the } \\
\text { method used to } \\
\text { prepare a graph of } \\
\text { function }\end{array}$ & $\begin{array}{c}\text { Clearly } \\
\text { understands the } \\
\text { method used to } \\
\text { prepare a graph of } \\
\text { a function }\end{array}$ & $\begin{array}{l}\text { Clearly understands } \\
\text { the method used to } \\
\text { prepare a graph of a } \\
\text { function. Offers } \\
\text { correct examples. }\end{array}$ \\
\hline $\begin{array}{l}\text { 1) Follows } \\
\text { procedure to } \\
\text { evaluate functions } \\
\text { of algebraic } \\
\text { expressions }\end{array}$ & $\begin{array}{l}\text { Is unable to } \\
\text { procedure to } \\
\text { evaluate functions } \\
\text { of algebraic } \\
\text { expressions }\end{array}$ & $\begin{array}{c}\text { Evaluates } \\
\text { functions of } \\
\text { algebraic } \\
\text { expressions } \\
\text { correctly some of } \\
\text { the time } \\
\end{array}$ & $\begin{array}{l}\text { Correctly evaluates } \\
\text { functions of } \\
\text { algebraic } \\
\text { expressions }\end{array}$ & $\begin{array}{l}\text { Correctly evaluates } \\
\text { functions of algebraic } \\
\text { expressions and show } \\
\text { all steps }\end{array}$ \\
\hline $\begin{array}{l}\text { 2) Follows } \\
\text { procedure sketch } \\
\text { the graph of the } \\
\text { function }\end{array}$ & $\begin{array}{l}\text { Is unable to sketch } \\
\text { the graph of the } \\
\text { function correctly }\end{array}$ & $\begin{array}{l}\text { Can only partially } \\
\text { graph the function } \\
\text { correctly. Has } \\
\text { trouble with other } \\
\text { parts. }\end{array}$ & $\begin{array}{l}\text { Can correctly } \\
\text { sketch the graph of } \\
\text { the function. }\end{array}$ & $\begin{array}{l}\text { Can correctly sketch } \\
\text { the graph of the } \\
\text { function. Provides } \\
\text { graph title, labels } \\
\text { axes, supplies units. }\end{array}$ \\
\hline $\begin{array}{l}\text { 3) Follows } \\
\text { procedure to solve } \\
\text { applied problems } \\
\text { using functions }\end{array}$ & $\begin{array}{l}\text { Cannot solve } \\
\text { problem that } \\
\text { applies function } \\
\text { concept }\end{array}$ & $\begin{array}{l}\text { Makes errors when } \\
\text { solving problem } \\
\text { using functions }\end{array}$ & $\begin{array}{l}\text { Correctly solves } \\
\text { applied problems } \\
\text { using functions by } \\
\text { following } \\
\text { procedure }\end{array}$ & $\begin{array}{l}\text { Correctly solves } \\
\text { applied problems } \\
\text { using functions by } \\
\text { following procedure. } \\
\text { Shows all steps. }\end{array}$ \\
\hline Communication & $\begin{array}{l}\text { Student could not } \\
\text { explain what he } \\
\text { was attempting to } \\
\text { do. }\end{array}$ & $\begin{array}{l}\text { Student explained } \\
\text { some of what was } \\
\text { done. Could not } \\
\text { explain all of the } \\
\text { solution correctly }\end{array}$ & $\begin{array}{l}\text { Student clearly } \\
\text { explained how the } \\
\text { problem was } \\
\text { solved. Clearly } \\
\text { understood the } \\
\text { function concept } \\
\text { and how to use it. }\end{array}$ & $\begin{array}{c}\text { Student clearly } \\
\text { detailed how the } \\
\text { problem was solved. } \\
\text { Clearly understood } \\
\text { the function concept. } \\
\text { Understood how to } \\
\text { plot and use the } \\
\text { graph. }\end{array}$ \\
\hline
\end{tabular}

\section{Performance Task Solution}

\section{Solution}

Volume of water discharged per day to sewer for 40 residences $=4.5(70)(40)=12600$ gals/day

Using conversions:- $1 \mathrm{gal}=0.1337 \mathrm{ft}^{3}$ and 1 day $=24(60)(60)=86400 \mathrm{sec}$

Then, volume of water discharged per sec $\mathrm{Q}=12600 /(0.1337)(86400)=1.09 \mathrm{ft}^{3} / \mathrm{sec}$

If the amount of water, $\mathrm{Q}$, in $\mathrm{ft}^{3} / \mathrm{sec}$, that a pipe flowing full can accommodate is given by

With $\mathrm{C}=120$ and $\mathrm{S}=0.015 \mathrm{ft} / \mathrm{ft}$, we can write

$$
\mathrm{Q}=0.432 \mathrm{CD}^{2.63} \mathrm{~S}^{0.54}
$$

$$
\begin{aligned}
& \mathrm{Q}=0.432(120) \mathrm{D}^{2.63}(0.15)^{0.54} \\
= & 18.61 \mathrm{D}^{2.63}
\end{aligned}
$$

"Proceedings of the 2005 American Society for Engineering Education Annual Conference \& Exposition Copyright $(\mathrm{C}$ 2005, American Society for Engineering Education”" 
(a) Writing $\mathrm{Q}$ as a function of $\mathrm{D}$ we have,

(b) Prepare table and plot graph as shown below.

$$
\mathrm{Q}(\mathrm{D})=18.61 \mathrm{D}^{2.63}
$$

\begin{tabular}{|l|c|c|c|c|c|c|c|c|c|c|c|c|}
\hline $\mathrm{D}(\mathrm{ins})$ & 2 & 4 & 6 & 8 & 10 & 12 & 14 & 16 & 18 & 20 & 22 & 24 \\
\hline $\mathrm{Q}\left(\mathrm{ft}^{3} / \mathrm{s}\right)$ & 0.17 & 1.03 & 3.00 & 6.41 & 11.5 & 18.6 & 27.9 & 39.7 & 54.1 & 71.3 & 91.6 & 115.2 \\
\hline
\end{tabular}

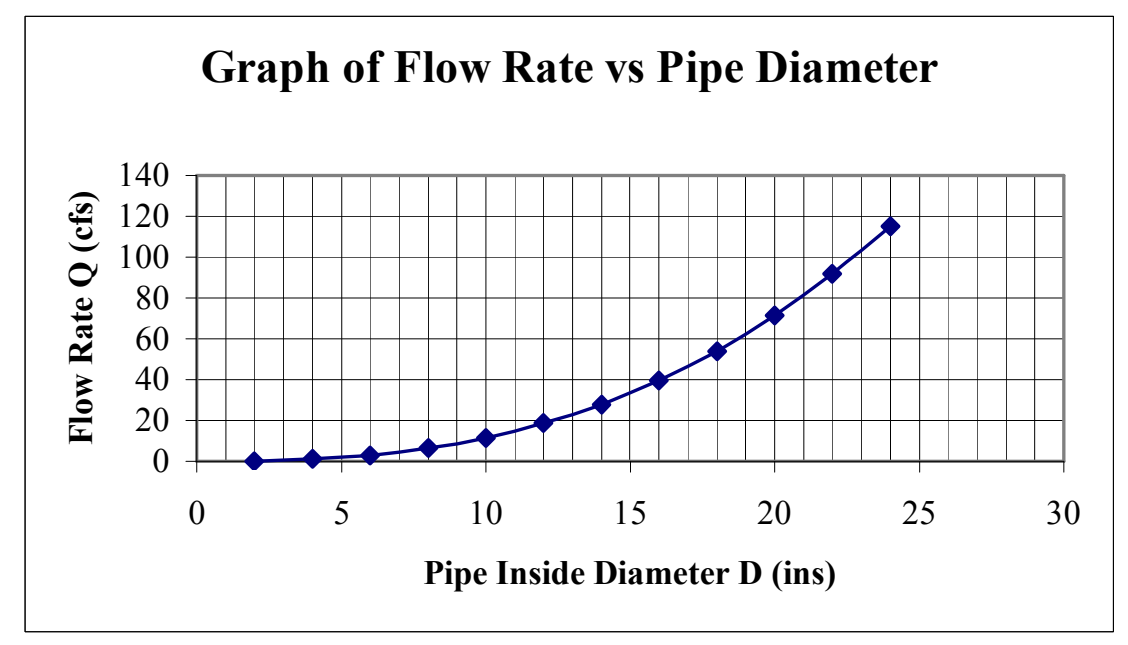

(c) Each vertical line on the graph intersects the curve once, therefore the curve is a plot of a function.

(d) (1) Entering the table with an average flow rate of $1.09 \mathrm{ft}^{3} / \mathrm{sec}$, select a 6 " diameter pipe. (Note that a 4" diameter pipe cannot accommodate $1.09 \mathrm{ft}^{3} / \mathrm{sec}$ )

(2) Entering the table with a Superbowl flow rate of $12 \times 1.09=13.08 \mathrm{ft}^{3} / \mathrm{sec}$, select a 12 "diameter pipe. 